\title{
Influências latinas na tipografia grega: análise histórica e abordagem não predatória de projetos multiescrita
}

\author{
Latin influences in Greek typography: historical analysis and non-predatory approach \\ of multi-script projects
}

\author{
Sérgio Luciano da Silva, Sérgio Antônio Silva
}

História da tipografia, tipografia multiescrita, design de faces gregas

\begin{abstract}
A escrita grega está envolvida em situações e processos históricos singulares e entrelaçada há milênios com a história da escrita latina. Uma dessas circunstâncias diz respeito ao estabelecimento e desenvolvimento da tipografia grega, que ocorreu quase exclusivamente fora do seu território. Em consequência disso, parte expressiva dos profissionais envolvidos nessa área não é grega. Paralelamente a isso, com o avanço da globalização dos meios de comunicação, a produção de fontes tipográficas em mais de uma escrita, principalmente latinas e gregas, tem se ampliado consideravelmente. Apoiado no percurso histórico da tipografia grega na Europa, este artigo tem dois objetivos. Destacar a relevância de expoentes estrangeiros que contribuíram para moldar a tipografia grega do século XV ao XX. E, a partir da observação e análise das criações tipográficas mais recentes de Matthew Carter e Hermann Zapf, extrair conceitos que possibilitem aos projetos de novas fontes multiescrita basearem-se na técnica e na história, sem predar a identidade cultural e a diversidade de cada escrita.
\end{abstract}

History of typography, multi-script typography, Greek typeface design

Greek script has been involved in singular historical situations and processes and interlaced with the history of Latin script for ages. One of those circumstances is related to the setting and the development of Greek typography, which happened almost exclusively out of its territory. As a consequence, a quite expressive number of professionals engaged in this area is not Greek. At the same time, with the globalization of the means of communication, the production of typographic fonts in more than one script, mainly Latin and Greek, has increased considerably. Having the history traced by Greek typography in Europe as premise, this article has two goals. To highlight the relevance of foreign outstanding professionals who contributed to the forging of Greek typography between the 15th and 20th centuries. And, by having the observation and analysis of Matthew Carter's and Hermann Zapf's most recent creations as a start, to obtain concepts that make it possible for projects of new multi-script fonts to be based on technique and history without jeopardizing the cultural identity and the diversity of each script.

\section{Introdução}

Quando pensamos nas civilizações grega e romana, considerando as suas contribuições para a cultura universal, uma sequência histórica se impõe. Os gregos estabeleceram pilares culturais para o desenvolvimento do ocidente. A eles se seguiram os romanos que, apesar de dominarem politicamente os primeiros, absorveram dos helênicos os mais diversos conhecimentos, inclusive costumes, sem preocupação com uma possível perda da sua própria identidade cultural. Como sabemos, o latim não se tornou a língua oficial do mundo grego, e pelo contrário, a conquista romana conduziu a uma maior influência do helenismo sobre Roma. É o que nos lembra as palavras de Horácio: "A Grécia vencida venceu o fero vencedor e introduziu as artes no agreste Lácio" (Hor. Ep. 2, 1, 156-7). Não resta dúvida da importância cultural que os próprios romanos creditavam aos gregos. No entanto, a relação entre estes dois povos há mais de 2000 anos foi mais complexa do que esta visão, em certa medida simplificadora. Acreditamos que esta interpretação de um período específico da história antiga (em que o Império Romano estava se constituindo e procurando expandir-se em todas as direções) pode ter se cristalizado em uma concepção mais ampla e equivocada de que a cultura latina é em todos os tempos e campos devedora à civilização grega.

Ocorre que, num período mais recente da história, numa área específica do conhecimento e da tecnologia, a condição de influência da cultura helênica sobre a latina em parte se inverteu. $\mathrm{O}$ ano de 
1454 inaugura a imprensa ocidental com a produção da Bíblia de 42 linhas, um ano após a queda de Constantinopla e a consequente dominação da Grécia pelo Império Otomano. Daquele momento em diante, os editores e impressores europeus, que estavam interessados em produzir obras em língua grega, puderam e passaram a ter entre seus colaboradores os exilados gregos (SATUÉ, 2004: 52). Desde então, a tipografia tem se mostrado um campo em que profissionais da escrita latina têm exercido forte influência, para o bem ou para o mal, sobre os rumos da imprensa grega.

A despeito das críticas internas e externas às diversas fontes produzidas neste período de mais de cinco séculos, bem como aos modelos que norteiam os rumos da criação tipográfica grega, somente nos últimos anos a Grécia passou a contar com uma produção interna (MACRAKIS, 1996: xiii-xxviii). Ainda assim o design de faces de tipo grego da atualidade não deixa de ser influenciado pelo que foi criado e pelos padrões estabelecidos anteriormente, principalmente por estrangeiros.

\section{Diferenciações a partir do nascimento: a primazia das chancelerescas}

Se as tipografias latina e grega surgiram quase que simultaneamente, a helênica iniciou sua existência em franca desvantagem em relação à praticada no restante do continente europeu romanizado. Incapaz de se estabelecer em seu próprio território, a tipografia grega tornou-se dependente do interesse de estrangeiros para se firmar enquanto tecnologia. Como afirma George D. Matthiopoulos (1996: 189), apesar dos esforços dos refugiados, a tipografia grega, produzida fora da Grécia, não teve a autonomia nem o suporte da infraestrutura econômica e cultural que uma nação livre pode oferecer. Desta maneira, apesar de os tipógrafos estrangeiros apoiarem-se no conhecimento dos exilados gregos, inclusive na forma da caligrafia dos seus escribas, o caminho europeu foi de adaptação da escrita grega aos padrões ocidentais de impressão.

Neste contexto, é necessário introduzir algumas delimitações quanto à estrutura formal das faces gregas a fim de melhor entender as suas diversas derivações históricas. Robert Bringhurst (2005: 298-299) divide didaticamente estas faces em três classes: ortópticas, cursivas e chancelerescas. As ortópticas são eretas e suas letras se constituem como unidades bem distintas entre si, como ocorre no estilo regular das faces latinas humanistas. As cursivas assemelham-se aos traços manuscritos, de forma corrente, e podem ser eretas ou inclinadas, como também ocorre com as itálicas latinas. As manuscritas chancelerescas são formadas por cursivas mais elaboradas, a partir da inclusão de muitas ligaduras, abreviações e formas alternativas. Uma vez que a mudança de uma cursiva para chanceleresca se dá, segundo Bringhurst, apenas pelo acréscimo desses elementos, podemos dizer que neste caso há apenas uma distinção de grau, e não de essência, entre essas duas classes. Ficaremos, portanto, aqui, atentos somente à distinção qualitativa entre ortópticas (figura 1) e chancelerescas (figura 2), dado que ao longo da história da tipografia essas duas classes competiram entre si, alternando-se na preferência tanto de profissionais quanto do mercado editorial.

Figura 1: Face grega ortóptica de Nicolas Jenson, 1472.

clari atque inclyri unt tam infamibus nos uoluptatibus deterretet.

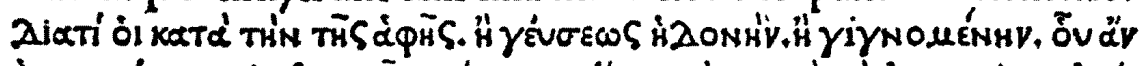

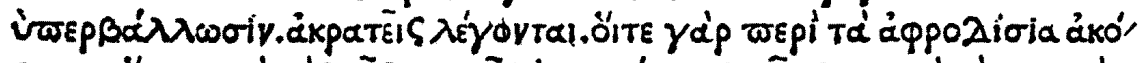
$\lambda \alpha 501$ öıt ซE

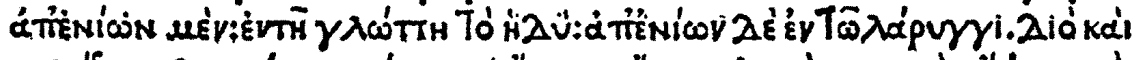

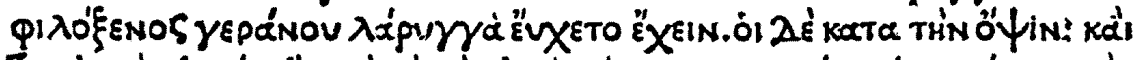

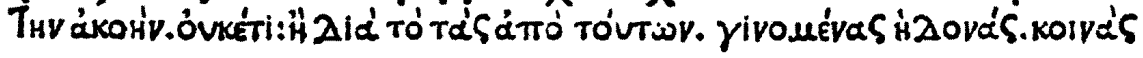

Figura 2: Face grega chanceleresca baseada na própria escrita de Aldo Manuzio, 1502.

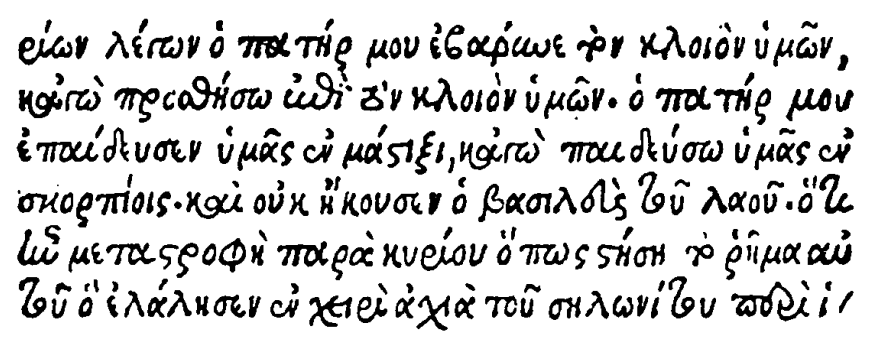


Historicamente essas classes de faces gregas tiveram uma evolução singular. Nas primeiras décadas da imprensa, as letras humanistas latinas minúsculas e as imperiais romanas maiúsculas (eretas, com poucas ligaduras, homogêneas e com textura legível) tornaram-se o modelo para fontes ortópticas, como a do espanhol Arnaldo Guillén de Brocar, do francês Nicolas Jenson e dos gregos Demetrios Damilas e Zacharias Kalliergis. Um exemplo disso está na figura 1. Na primeira linha podemos ver a cópia de um texto impresso em 1472, com uma fonte latina em estilo humanista, e nas linhas seguintes texto em grego com uma fonte ortóptica de Nicolas Jenson. Mas já na virada do século XV para o XVI as chancelerescas ganharam destaque na produção de fontes gregas, para atender ao crescente mercado europeu de livros impressos. Isto se deve em grande parte à influência que o editor, tipógrafo e livreiro, Aldo Manuzio exerceu sobre seus concorrentes e sucessores após estabelecer para si um sólido e bem-sucedido mercado editorial (LEONIDAS, 2002: 77-78). Parte das edições gregas de Manuzio era impressa com matrizes produzidas por Francesco Griffo, que, segundo Takis Katsoulidis (1996: 153), se inspirava na escrita manual de escribas gregos contemporâneos como Immanuel Rhusotas. Esta não seria uma boa opção uma vez que, de acordo com Katsoulidis, poderiam ser utilizadas melhores referências como a dos antigos mestres calígrafos do período bizantino. Independentemente da crítica de estudiosos, como Robert Proctor (1900), acerca da escolha de Manuzio ter impedido por muito tempo a evolução das letras gregas em direção a uma regularização tipográfica, o fato é que o sucesso comercial de Manuzio consagrou o padrão de fontes com muitas abreviações, ligaduras e a busca por imitar os traços manuscritos. O triunfo da empresa Aldina bloqueou o desenvolvimento da vertente ortóptica por duzentos anos, ao mesmo tempo em que impulsionou a chanceleresca e garantiu o êxito das faces de profissionais como Claude Garamond (figura 3) e Robert Granjon, alinhadas conceitualmente com seu estilo.

Figura 3: Face Grecs du Roi de Claude Garamond, 1550. Os círculos destacam três elaboradas abreviaturas, complexas e trabalhosas para serem produzidas em tipos de metal.
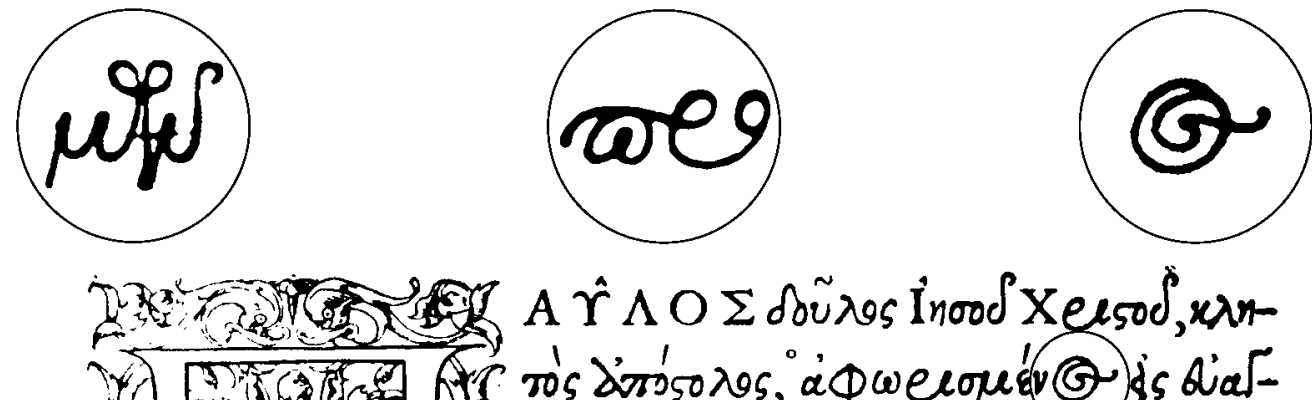

$A \hat{\Upsilon} \Lambda O \Sigma$ doũ $\lambda \theta s$ Inood Xeesod, $x \lambda n-$

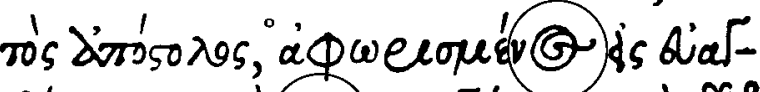

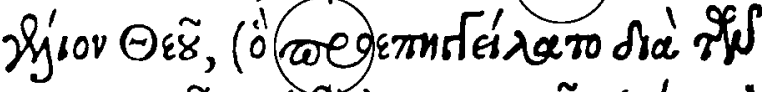

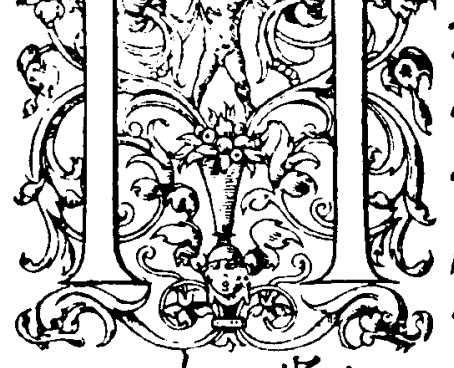

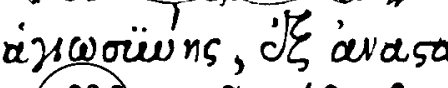

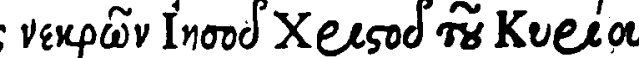

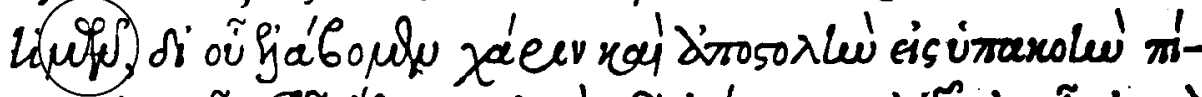

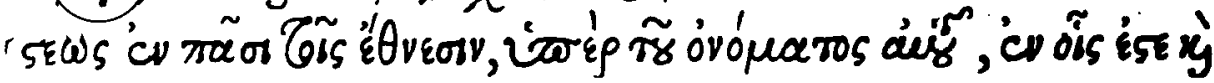

\section{0 giro e a trajetória britânica: a retomada das ortópticas}

Em 1756, Alexander Wilson, um escocês de muitas profissões (médico, astrônomo e puncionista), concluiu uma face que reduzia o número de ligaduras e formas alternadas, mas ainda mantinha em certa medida o espírito das chancelerescas. A fonte baseada nessa face foi especialmente produzida para uma edição de Homero (1756-58) encomendada pela Universidade de Glasgow (figura 4). No mesmo período, o calígrafo e impressor inglês, John Baskerville (1706-75), inserido na cultura do século XVIII e 
influenciado pelo ambiente racionalista de seu tempo, cria faces latinas que se afastam cada vez mais do estilo cursivo, sendo também marcadas por um eixo mais vertical. Em 1761, Baskerville terminou o projeto de uma nova face grega para a Oxford University Press (figura 5). Segundo John H. Bowman (1996: 129), esta foi a primeira tentativa inglesa de eliminar as tradicionais ligaduras. Por sua vez, Matthew Carter (1996: 185) aponta a pressão econômica como o motivo para o abandono de fontes que contivessem muitos elementos e demandassem altos custos com compositores e revisores. Independente dos diversos fatores históricos, culturais e econômicos, o fato é que as características chancelerescas foram gradualmente eliminadas dos novos projetos tipográficos.

Figura 4: Face de Alexander Wilson. Trecho da edição de Robert e Andrew Foulis, da obra lliad, de 1756.

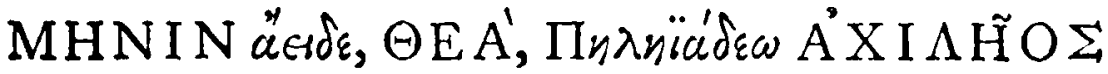

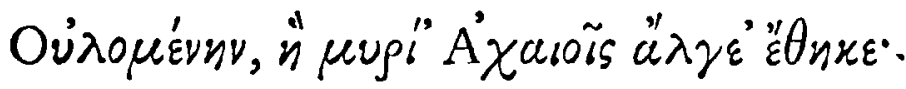

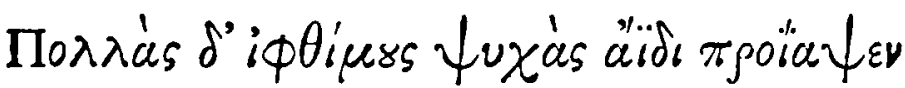

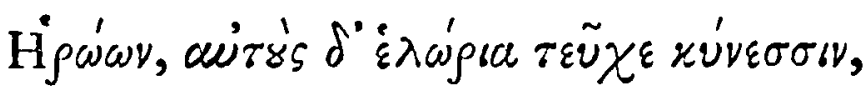

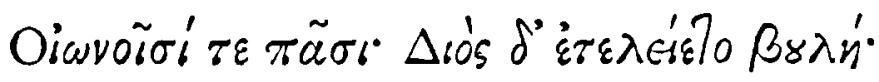

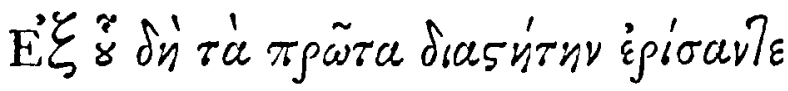

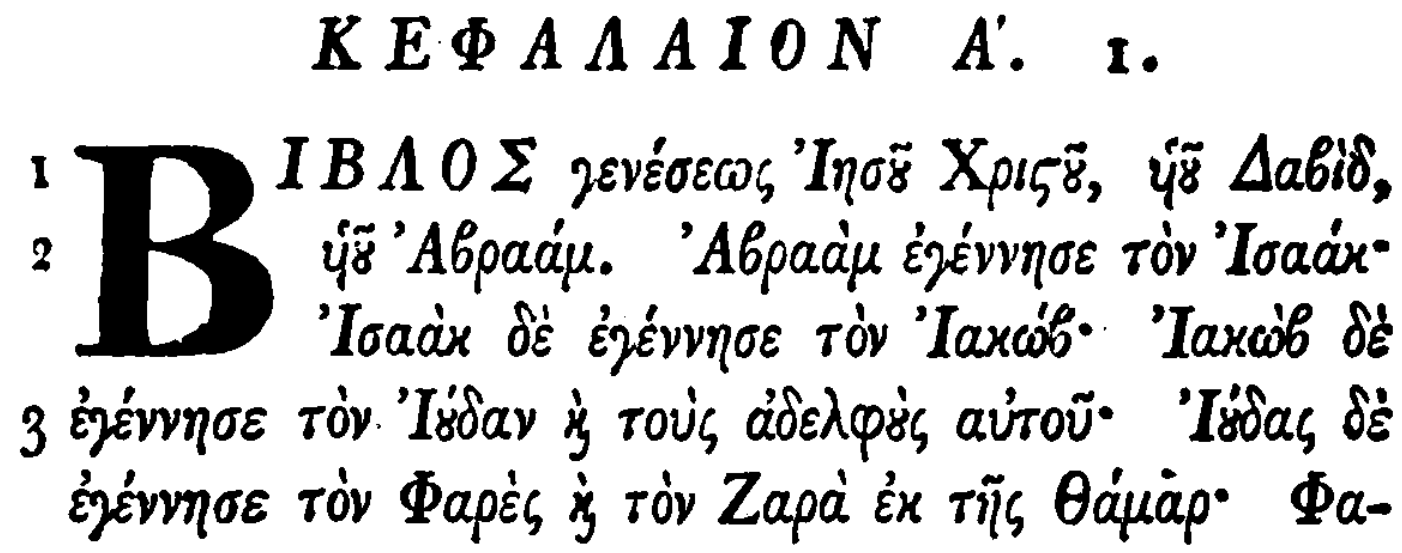

É nesse cenário que a Inglaterra se destaca com uma contribuição singular aos rumos da criação tipográfica grega, contribuição essa que se estenderá do século XVIII ao XX. Matthew Carter (1996: 185) identifica a face grega de Baskerville como o ponto de transição de projetos tipográficos em que a influência da tipografia latina se torna mais acentuada em detrimento da caligrafia grega. Carter lembra que entre a criação da face de Wilson e da face de Baskerville passam-se poucos anos, mas a segunda tem, como um de seus aspectos distintivos, maior uniformidade no tamanho das minúsculas, o que caracteriza uma preocupação com a regularização e a padronização tipográfica. Uma simulação feita na figura 6, a partir de parte das figuras 4 e 5, ajuda a perceber algumas diferenças. Na parte de cima da figura 6, podemos notar como é necessário um número maior de linhas para delimitar as diversas alturas das letras da face de Wilson. $E$ na parte de baixo, a face de Baskerville é muito mais regularizada: a letra $\beta$ tem a mesma altura das ascendentes do $\delta$, e $\lambda$, letras como $\eta$ e $\mu$ têm descendentes de tamanho aproximado e o bojo do $\varphi$ é mais homogêneo com o bojo das letras $\delta, 0, \rho$ e $\sigma$. 
Figura 6: Simulação das principais linhas de auxílio na construção de glifos usando parte das imagens das figuras 4 e 5 .
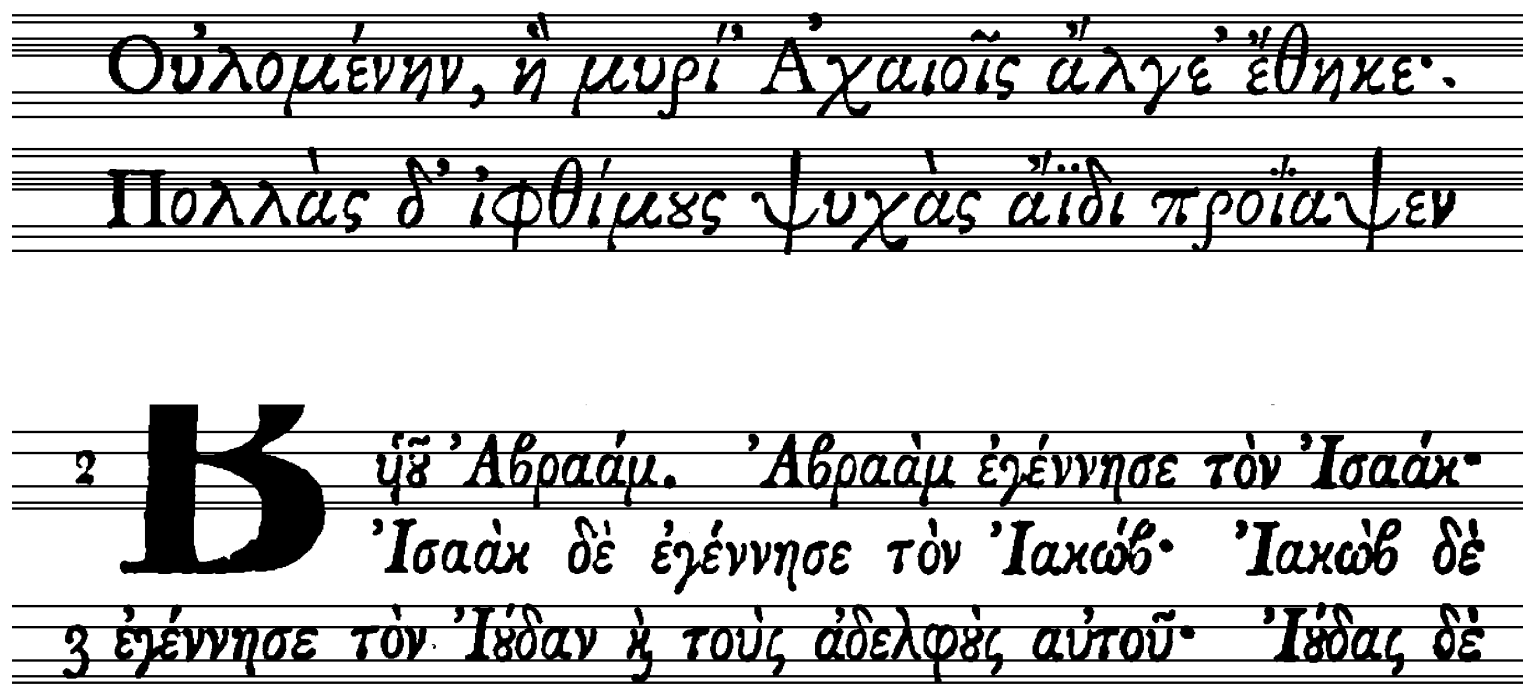

$\mathrm{Na}$ esteira de Baskerville diversos acadêmicos criaram faces gregas que se tornaram muito populares, influenciando cada qual os profissionais e o mercado da geração seguinte. Estão entre eles o professor de grego Richard Porson (1757-1808) criador da Porson Greek, o bibliotecário Robert Proctor (1868-1903) criador da Otter Greek, e outro bibliotecário sucessor de Proctor no Museu Britânico, Victor Scholderer (1880-1971), criador da New Hellenic.

$\mathrm{O}$ que estes homens tinham em comum (além de serem ingleses e terem profissões voltadas para os estudos gregos) era o fato de não serem tipógrafos profissionais. No entanto, a fundamentação teórica que estes estudiosos tinham em relação à língua e cultura grega pode ser comparada com a de Aldo Manuzio e reforçam nossa conviç̧ão da importância de se ter conhecimento e envolvimento com a cultura, a história e a língua quando a intenção é o projeto tipográfico em uma escrita estrangeira. Além disso, o fato de serem ingleses, vivendo numa época em que a caligrafia era ainda valorizada em seu país, indica um fator de ordem prática: a habilidade manual. A Porson Greek, por exemplo, foi gravada pelo puncionista inglês Richard Austin, em torno de 1786, a partir de referências da própria escrita manual de Richard Porson, um amante da caligrafia (figura 7).

Figura 7: Face Porson Greek. Trecho da edição de Cambridge da obra The Oresteia of Aeschylus, de 1920.

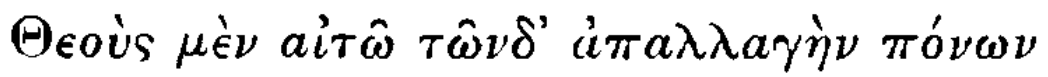

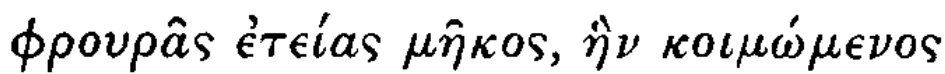

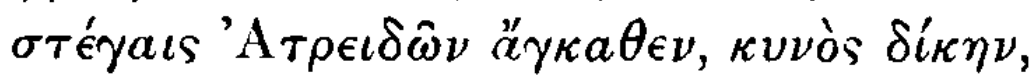

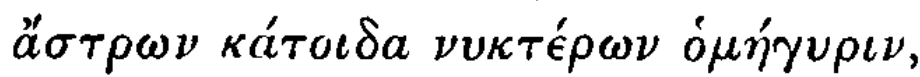

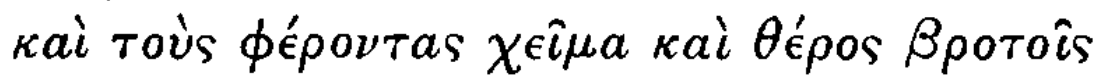

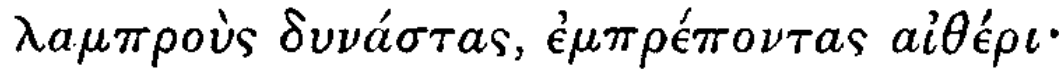

Robert Proctor, por sua vez, inspirou-se na face Complutensiana de Arnaldo Guillén de Brocar, de quatrocentos anos antes, que ele considerava a melhor fonte grega já produzida (PROCTOR, 1900: 144). Assim, num elogio e retomada das ortópticas, Proctor desenhou a sua Otter Greek, gravada pelo puncionista Edward Prince em 1904 (figura 8). Como afirma Bowman (1996: 143), o que Proctor fez foi copiar a Complutensiana, fazendo um mínimo de alterações e acrescentando as maiúsculas, que não existiam na original. 


\section{AГAMEMNONOC YTTOӨE $\leqslant \mid C$

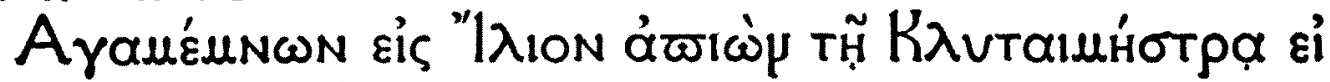

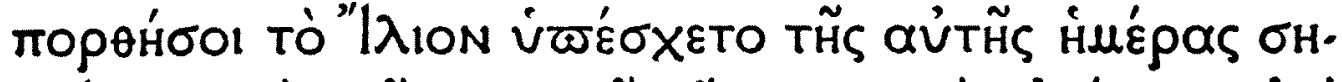

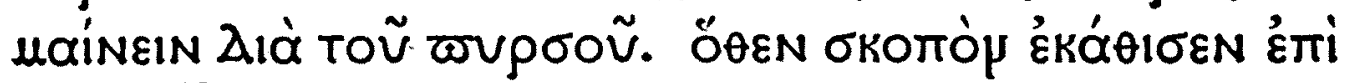

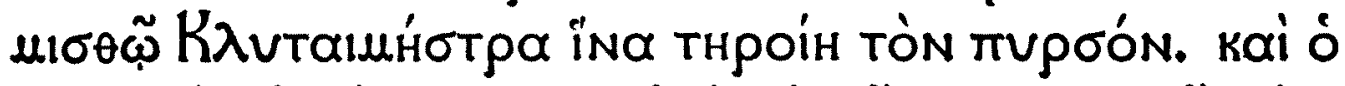

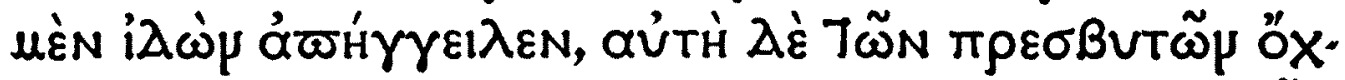

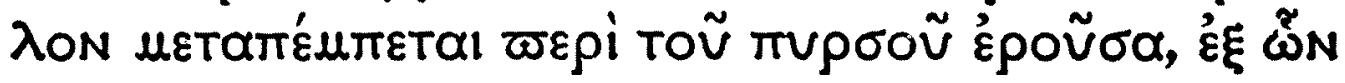

Victor Scholderer, que, após a morte de Proctor, o substitui em seu cargo no Museu Britânico, concebe a face New Hellenic a partir dos resultados de suas pesquisas históricas em trechos gregos de uma edição do Macrobius (impressa por Giovanni Rosso em 1492). A fonte é gravada e concluída pela Monotype Corporation em 1927. Com Scholderer, temos novamente a escolha de outra ortóptica pré-aldina, resgatada do passado e usada como modelo para uma nova face de tipo (figura 9).

Figura 9: Face New Hellenic, baseada no desenho de Victor Scholderer. Trecho de Thucidydes' The funeral oration of Péricles, de 1929.

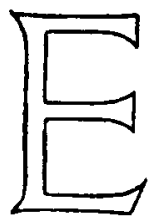

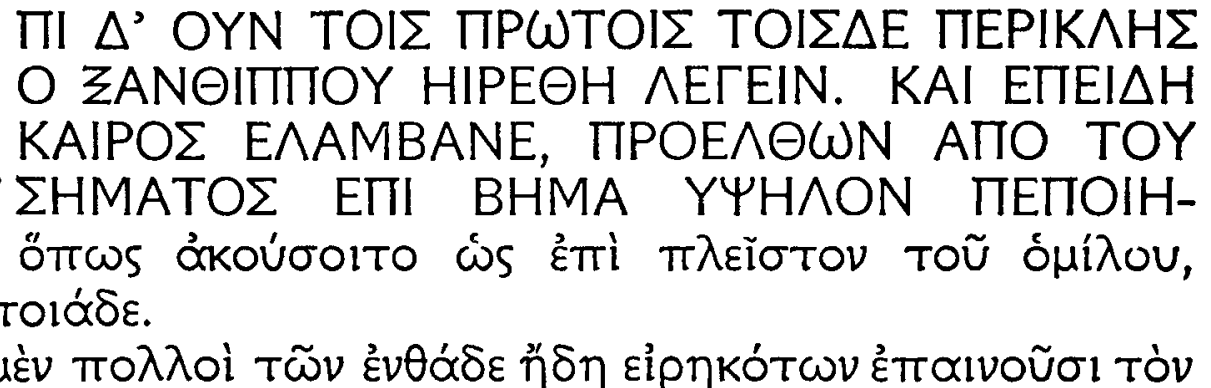

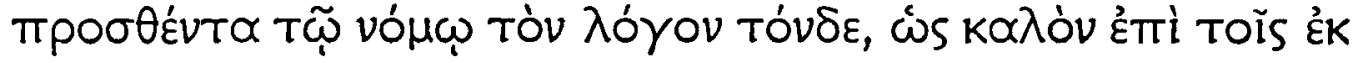

As figuras 7, 8 e 9, quando comparadas com o modelo aldino, visto nas figuras 2 e 3, evidenciam o afastamento do ideal chanceleresco promovido pela tipografia inglesa, ao longo dos séculos XVIII e XIX e início do XX, em busca de uma estrutura mais regularizada, menos complexa e próxima dos critérios da tipografia latina já estabelecidos e praticados desde a Renascença. A vertente inglesa garantia às faces gregas tanto uma simplificação e economia nas diversas etapas de produção e utilização das fontes, quanto um melhor amálgama entre textos latinos e gregos, quando utilizados em obras que incorporassem as duas escritas.

\section{Os desdobramentos de uma nova concepção italiana e francesa}

Takis Katsoulidis (1996: 155) afirma que apesar de muitos tipógrafos terem seguido o caminho aberto por Baskerville, foi o italiano Giambattista Bodoni (1740-1813) e a família francesa Didot que "moldaram" a tipografia grega no século XIX. Mas, na verdade, Bodoni e os Didot também fazem parte da vertente que se afasta da concepção chanceleresca. Bodoni, que foi um puncionista de latinas prolífico, também criou muitas faces de tipo gregas. E é por essa produção que o mesmo é criticado tanto por Gerry Leonidas (2002: 81) quanto por Hermann Zapf (1996: 13). A crítica de ambos converge para um mesmo ponto. Zapf reconhece a contribuição de Bodoni no projeto de faces latinas (regulares e itálicas), mas vê em suas faces gregas problemas de espaçamento, falta de consistência entre as letras e a inapropriada inclusão de curvas barrocas (figura 10). Leonidas (2002: 90), por seu lado, considera que falta a Bodoni a ideia de conjunto em 
uma face de tipo, uma vez que suas letras parecem feitas apenas para a apreciação estética. Apesar de todas essas inconsistências no projeto Bodoniano, foi, no entanto, uma variação inclinada do seu estilo que passou a ser desenvolvida e explorada por impressores alemães e que, segundo Leonidas (2002: 82), mantém-se viva ainda hoje.

Figura 10: Face grega de Giambattista Bodoni. Trecho de Longus, 1786. As setas indicam curvas pouco apropriadas para uma face de tipo feita para textos corridos.

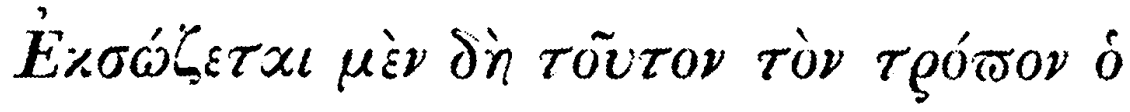

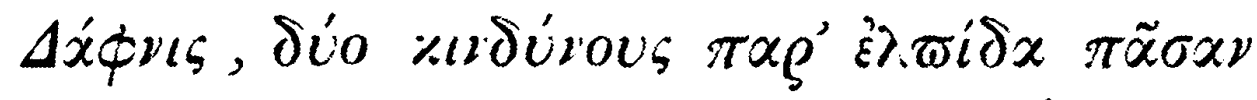

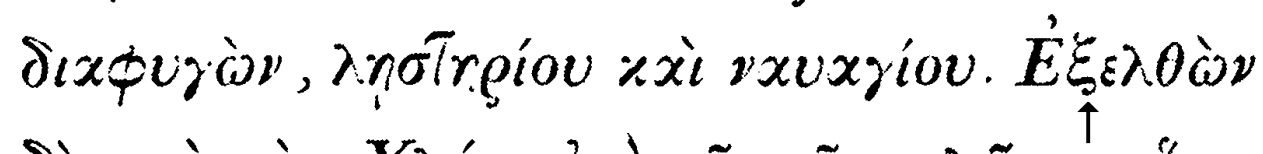

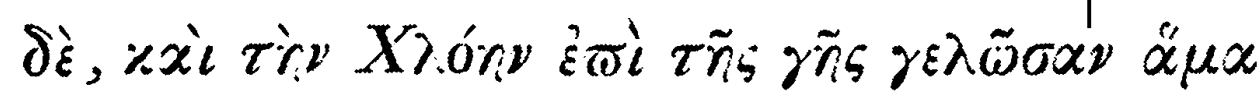

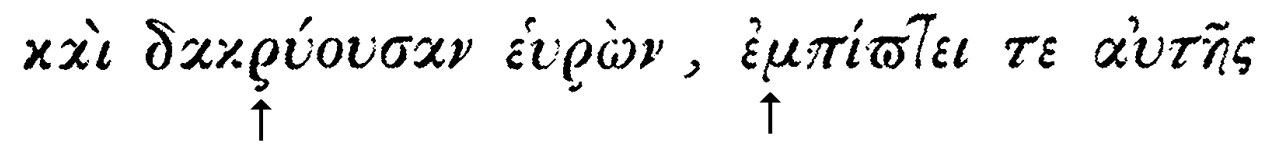

A família Didot competia em Paris com Giambattista Bodoni (ZAPF, 1996: 13). A ela pertencem vários nomes importantes para a história da tipografia: Ambroise François Didot (1730-1804), Pierre Didot (1761-1853), Firmin Didot (1764-1836) e especialmente Ambroise Firmin Didot (1790-1876), que era um entusiasta da cultura helênica. No entanto, Zapf também considera deficientes as faces gregas desenvolvidas por eles. Particularmente com relação a Firmin Didot, ele vê problemas associados às direções do eixo das letras, que se resolveriam caso o puncionista estivesse atento ao movimento da caneta de pena ou de junco no momento do desenho das letras. Na figura 11, a versão digital de uma fonte de Firmin Didot, projetada por Takis Katsoulidis e digitalizada por George Matthiopoulos, difere daquela de que nos fala Zapf, apresentando um eixo regularizado e mantendo-o quase vertical (letras $\delta, o, \rho$ e $\sigma$ ), ou vertical (letra $\theta$ ). No entanto, essa versão mantém, como na original de Didot, alguns traços mais finos (letras I, V e т) e outros mais espessos (letras $\lambda$ e X), contrariando os movimentos de uma caneta de pena. Já, especificamente sobre o estilo de Ambroise Firmin Didot, Leônidas o considera consistente, sustentando que sua face tornou-se a mais usada na Grécia no século XX (LEONIDAS, 2002: 82).

Figura 11: Face GFS Didot. Versão digital de 1994 produzida para a Greek Font Society. Esta versão preserva as espessuras dos traços originais de Firmin Didot, não coerentes com traços de origem caligráfica.

$$
\begin{aligned}
& \mathrm{AB} \mathrm{B} \Delta \mathrm{EZH} \Theta \mathrm{IK} \Lambda \mathrm{M} \mathrm{N} \Xi \mathrm{O} \Pi \mathrm{P} \Sigma \mathrm{T} \Upsilon \Phi \mathrm{X} \Psi \Omega \\
& \alpha \beta \beta \gamma \delta \varepsilon \zeta \eta \theta \vartheta \iota x \lambda \mu \nu \xi o \pi \rho \varsigma \sigma \tau \nu \varphi \phi \chi \psi \omega
\end{aligned}
$$

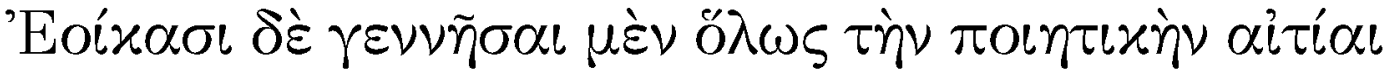

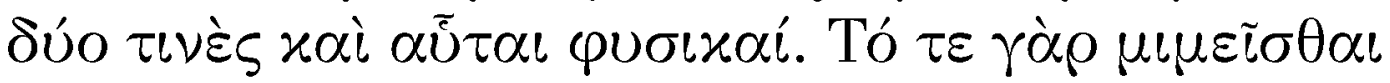

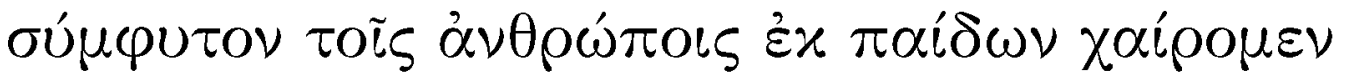
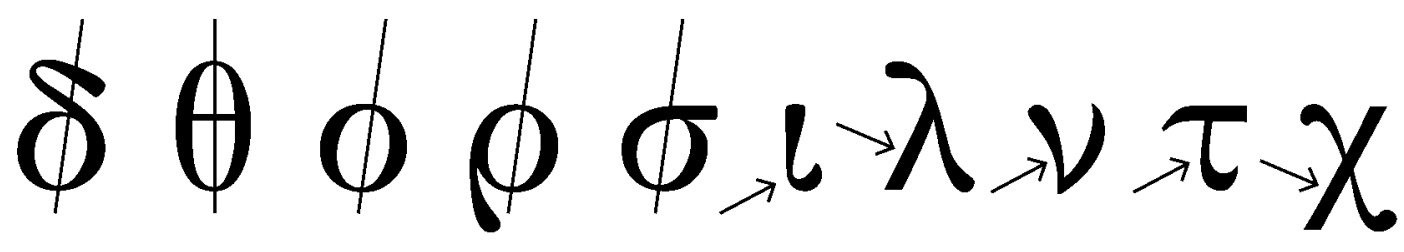


\section{0 século XX: a latinização versus uma abordagem não predatória de projetos multiescrita}

Com o aumento da mecanização, a ampliação dos mercados editoriais e o crescimento de empresas especializadas em produção e comercialização de fontes, como a Monotype e a Linotype, os rumos da tipografia grega cada vez mais foram influenciados por decisões de caráter mercadológico e menos por procedimentos oriundos da técnica ou da pesquisa histórica e cultural. Entre os diversos designers de face no século XX que se dedicaram à criação de faces gregas, quatro são emblemáticos para o nosso tema, devido às suas destacadas atuações no âmbito das escritas latina e grega. São eles o holandês Jan van Krimpen (1892-1958), os ingleses Eric Gill (1882-1940) e Matthew Carter (1937-) e o alemão Hermann Zapf (1918-). A análise de algumas de suas faces, bem como a busca pelos propósitos que fundamentaram suas criações, lançam luz sobre alguns parâmetros que ainda guiam o universo tipográfico grego na atualidade e sobre outros que podem subsidiar uma nova abordagem projetual.

Jan van Krimpen, como outros designers da sua época, tinha interesse em homogeneizar suas faces gregas e latinas, tornando-as mais apropriadas para utilização em conjunto. Obras impressas contendo mais de uma escrita tornaram-se comuns já no fim do século XV com Manuzio e suas publicações que incorporavam latim e grego. Pouco tempo depois, no início do século XVI, já estavam sendo publicadas obras como a Bíblia Complutensiana Poliglota, em grego, latim e hebraico. No entanto, ao longo dos séculos, com o avanço da globalização, a necessidade de fontes que atendessem aos propósitos de mais de uma escrita em uma mesma obra, aliou-se à preocupação projetual de tornar as letras dessas escritas mais harmônicas entre si. Em Krimpen, a aproximação formal geralmente era estabelecida a partir de uma adequação da escrita grega à latina, já que normalmente a face latina, por questões de mercado, era desenvolvida primeiro. Infelizmente, este procedimento incremental ${ }^{1}$ tornava tanto o designer quanto $o$ design da face grega reféns das características estabelecidas no projeto latino precedente. Devemos atentar para o fato de que no início do século XX a tipografia ainda era um ofício executado em ligas de metal. Alterar as matrizes de uma fonte concluída e comercializada, para produzir novos tipos, além de um processo longo, era muito oneroso. Dessa maneira, o design incremental, apesar de suas limitações, se justificava, tanto do ponto de vista técnico quanto do mercadológico.

Um exemplo de design incremental em Krimpen é o da face Romulus grega, de 1937, produzido para a empresa holandesa Enschedé, executado seis anos após a finalização da Romulus latina. $O$ projeto de Krimpen, em parceria com o puncionista alemão Paul Rädisch, acrescentou serifas em letras minúsculas como $\circ \beta, \gamma, \delta, \eta, \mu$ e $\rho$. $O$ resultado tornou as duas faces (a latina e a grega) visualmente mais amalgamadas, quando aplicadas lado a lado (figura 12, parte de baixo). Porém, este tipo de solução tem um preço. Crescem os problemas com espaçamento entre letras como $\eta$ e $\mu$, que tendem a causar colisões nas serifas de suas descendentes (detalhe circulado na figura 12). Além disso, torna as letras gregas artificiais, uma vez que as minúsculas não são, tradicionalmente, serifadas, mesmo em faces cujas maiúsculas contêm serifas. Outro exemplo de projeto incremental é o de Eric Gill da face Perpetua grega. Gill recorre ao mesmo artifício de Krimpen para a criação de uma correlata grega à Perpetua latina, que padece de deformidades equivalentes às da face de Krimpen (figura 13).

O papel desempenhado por Matthew Carter no cenário tipográfico grego do século XX é relevante para a compreensão desses acontecimentos, tanto do ponto de vista prático quanto do teórico. Isto porque, Carter, por um lado, participou ativamente nos anos 1970 da criação de faces gregas que mimetizavam características da tipografia latina (como o caso das serifas em minúsculas). Por outro, mais recentemente ele se defendeu, enquanto designer, sobre a criação de faces gregas não originais, mas adaptadas. Num simpósio sobre tipografia grega, realizado em 1995, em Atenas, Carter afirmou que este tipo de adaptação foi uma exigência que o próprio mercado interno grego em crescimento fez aos designers, na medida em que este mercado buscava uma aproximação da tipografia grega com os ideais ocidentais (CARTER: 1996, 177). A posição de Carter também é crítica a esse respeito, tanto que ele (posteriormente a esse período em que trabalhou para a Linotype em projetos gregos) procurou um caminho alternativo, produzindo fontes que, de algum modo, se referenciavam a modelos históricos consistentes. Um exemplo disso é a sua Wilson grega, de 1995, baseada na original de Alexander Wilson, citada anteriormente na figura 4.

\footnotetext{
${ }^{1}$ Para uma análise acerca dos métodos de criação incremental e simultâneo, ver o artigo dos autores, Considerações metodológicas sobre design tipográfico em multiescrita, citado nas Referências.
} 
Figura 12: Faces Romulus Greek (1937) e Romulus Latin (1931) de Jan van Krimpen, com punções de Paul Rädisch.
A B $Г \triangle E Z H \Theta I K \wedge M N 玉 O \Pi P \Sigma$ $\mathrm{T} Y \Phi \times \Psi \Omega$
A B C D E F G H I K L M NOP Q R $S T U V W X Y Z$
$\alpha \beta \gamma d \varepsilon z \eta \theta i k \lambda \mu v z o n p o s \tau u \phi X \Psi w$
abcdefghijklmnopqrstuvwxyz
fbfffifflfhfifkfl
1234567890

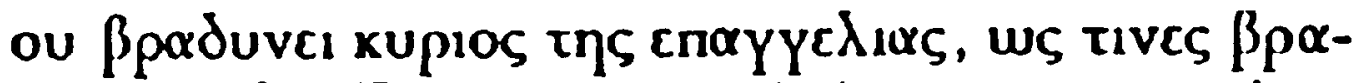
Non tardat Dominus promissionem suam, sicut

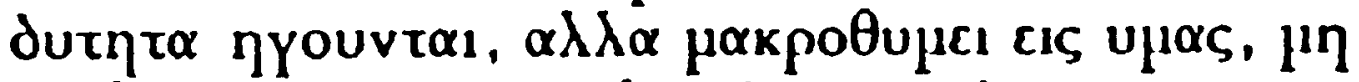
quidam existimant: sed patienter agit propter vos,

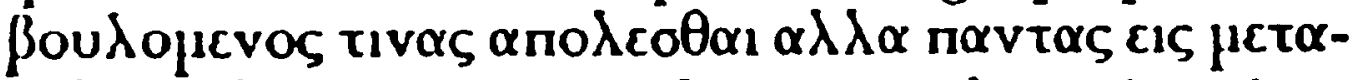
nolens aliquos perire, sed omnes ad ponitentiam

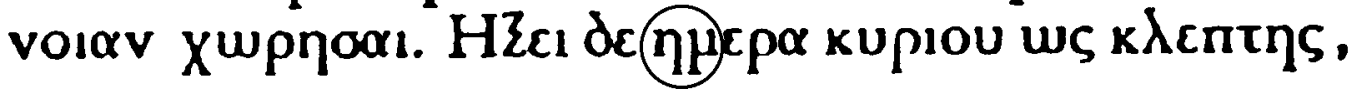

Figura 13: Faces Perpetua Greek e Perpetua Latin de Eric Gill. A versão latina foi originalmente desenhada para a Monotype em 1925.

$$
\begin{aligned}
& \Gamma \Delta \Theta \Lambda \Xi \Pi \Sigma \Phi \Psi \Omega \\
& \text { A CDEFG IJKLM } \\
& \text { abcdefgh kl } \\
& \text { а } \beta \delta \epsilon \zeta \eta ө к \lambda \mu \xi п р \sigma
\end{aligned}
$$

Ao nos apoiarmos no argumento de Carter e na defesa que Macrakis (1996, xx) faz dos valores e da cultura grega, podemos entender esta adequação das formas das letras gregas às das latinas como, na expressão de Macrakis, uma "latinização" da escrita helênica, que pode ter consequências nefastas não só para a tipografia grega, mas também para a identidade cultural de sua nação. Principalmente quando, além da inclusão das serifas nas minúsculas, designers estrangeiros e gregos passaram, na criação de suas faces, a substituir letras gregas como $\zeta, \eta, v$, $\zeta$, $u$ e $x$ pelas letras latinas $z, n, v, s, u$ e $x$, baseados numa pretensa semelhança formal entre cada um desses pares. 
A busca por um caminho mais equilibrado, como faz Carter, ocorre também no trabalho de Hermann Zapf, um calígrafo e designer que tornou-se referência mundial pela excelência das suas criações tipográficas. Zapf (que nasceu em 1918) não somente atravessou todo o século XX transpondo as diversas mudanças da tecnologia (tipografia em metal, fotocomposição e digital), mas incursionou ativamente em todas elas, criando faces latinas e gregas e participando de diversos projetos no âmbito da tecnologia digital aplicada à tipografia. Além disso, como Carter, ele pesquisou e escreveu sobre a história da tipografia grega, o que faz também dele um observador e analista privilegiado pela sua condição de tipógrafo. Na essência, Zapf considera que não devemos copiar simplesmente o passado, porém estudá-lo para entender seus erros e acertos e usar esse conhecimento no desenvolvimento de novos projetos tipográficos (ZAPF, 1996, 29).

Diversas foram as faces gregas criadas por Zapf ao longo de sua carreira, algumas delas ainda de maneira incremental. O objetivo aqui não é relacioná-las, mas procurar capturar, a partir de um projeto tipográfico específico (o da face Euler), elementos conceituais que estão contidos em seu trabalho, isto é, expostos no desenho de suas letras.

O projeto Euler foi desenvolvido para a American Mathematics Society (AMS) em colaboração com Donald E. Knuth da Universidade de Stanford, entre os anos de 1980 e 1986. A seguir alguns aspectos distintivos que extraímos da observação e análise de detalhes construtivos da face Euler e que, acreditamos, estão em consonância com preceitos defendidos por Zapf:

1. O projeto foi implementado no método simultâneo, isto é, as letras das duas escritas foram concebidas ao mesmo tempo por Hermann Zapf. Assim, não existiu adequação forçada dos desenhos de uma escrita aos desenhos de outra (figura 14). O número reduzido de serifas nas letras latinas (incluindo maiúsculas) diminuiu o contraste entre as letras nas duas escritas (ver setas, na figura 14, indicando a ausência de serifas onde as mesmas normalmente ocorrem). Como consequência, textos produzidos em latim e grego se combinam de maneira harmônica e discreta, somente chamando a atenção do leitor para a mudança de escrita quando, seguindo o caminho natural da leitura, encontra-se uma palavra em grego (figura 15).

2. A busca por uma regularização das letras gregas proporcionou um desenho mais uniforme e menos complexo, aproximando-se do ideal da vertente ortóptica. A letra $\mathrm{x}$, latina, na primeira linha da figura 16 tem a mesma altura das letras gregas sem ascendentes nem descendentes. Na segunda linha estão dispostas letras gregas que contêm ascendentes e descendentes. Todas têm uniformidade entre suas alturas, mas não estão obrigadas a seguirem as medidas exatas das latinas, como $\circ$ b e $\circ$ p. Isto mostra autonomia no desenho das letras gregas.

3. O domínio do desenho com traços caligráficos livrou Zapf de incorrer nos erros que ele critica em Didot. Na figura 17, à esquerda, temos as letras gregas I, $\lambda, \mathrm{V}, \mathrm{T}$ e X configuradas em GFS Didot. As setas indicam os problemas de espessura da Didot (já apontados anteriormente). À direita, as mesmas letras configuradas em Euler, com as setas apontando suas espessuras bem proporcionadas.

4. O ducto das letras da Euler tem espessura variável, típico daqueles produzidos com canetas caligráficas de ponta larga. Na figura 18 temos a simulação do caminho que percorreria a pena para desenhar as letras. A característica de espessura variável da pena também se verifica nos traços mais grossos, próprios dos movimentos descendentes e mais finos dos movimentos ascendentes. Este tipo de traçado, que tem como modelo as faces cursivas e chancelerescas, acreditamos, é o componente cultural que Zapf preserva na Euler, sem entrar em conflito com o padrão de regularização ortóptica das formas do item 2 desta lista.

5. Contrário à tendência latinizante de substituir letras gregas por latinas formalmente semelhantes, Zapf procura preservar os traços e as identidades de cada escrita (figura 19). 
Figura 14: Maiúsculas e minúsculas gregas e latinas da face Euler. As maiúsculas latinas têm um número reduzido de serifas.
A B CDEFGHIJKLMNOPQRSTUVWXYZ abcdefghijklmnopqrstuvwxyz $\Gamma \Theta \wedge \Xi \Pi \Sigma \curlyvee \Phi \Psi \Omega \Delta$
$\alpha \beta \gamma \delta \varepsilon \zeta \eta \theta \vartheta \iota \kappa \lambda \mu \nu \xi \pi \rho \sigma \tau v \phi \varphi \chi \psi \omega$
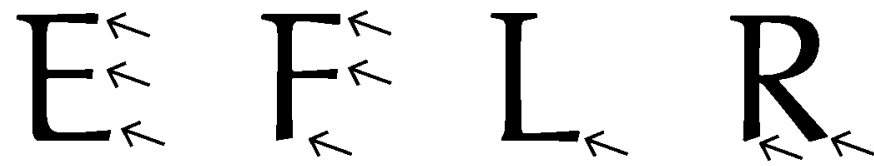

Figura 15: Exemplo de texto multiescrita na face Euler. As palavras em alfabeto grego estão em harmonia com as palavras em alfabeto latino.

Caractere vem do substantivo grego $\chi \alpha \rho \alpha \kappa \tau \eta \rho$, que significa sinal gravado, impresso. A palavra glifo vem igualmente do grego $\gamma \lambda \cup \phi \omega$, verbo que significa cinzelar, esculpir, gravar.

Figura 16: Uniformidade e regularidade das letras gregas na face Euler.

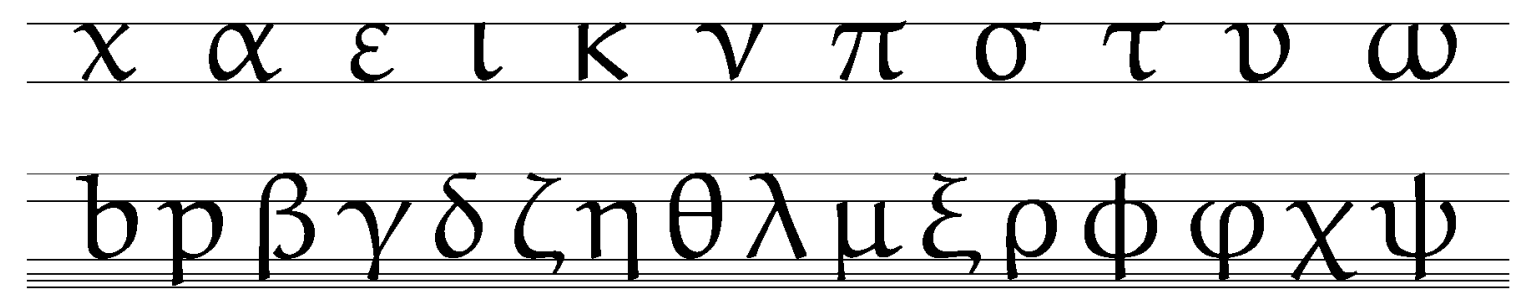

Figura 17: Comparação entre a deficiência no traçado de algumas letras na face GFS Didot (esquerda) e o equilíbrio nas linhas das mesmas letras na face Euler (direita).

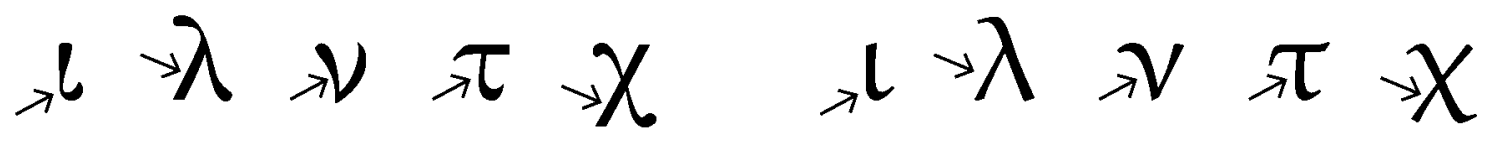

Figura 18: Simulação por meio de setas do movimento da pena e da variação de espessura do ducto na face Euler.
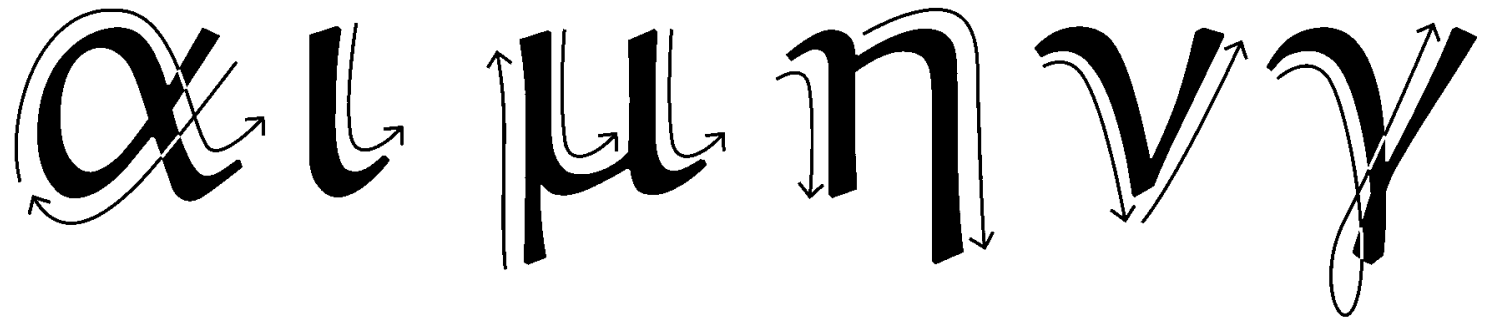
Figura 19: Distinção de letras, formalmente semelhantes, no alfabeto latino e grego, dentro da face Euler.

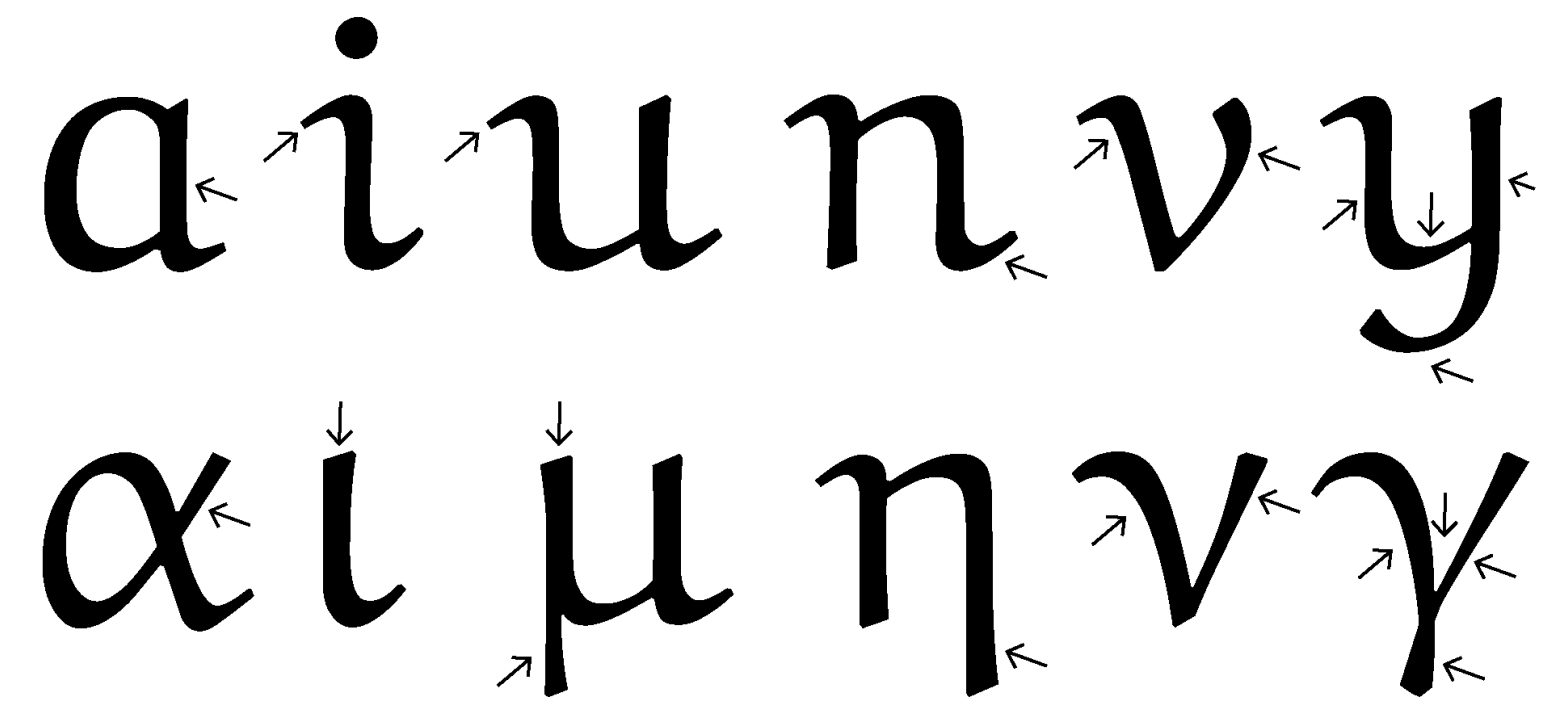

\section{Considerações finais}

Se olharmos novamente para o século $\mathrm{XV}$, com a visão ampliada do percurso histórico percorrido, percebemos que homens como Gutenberg e Manuzio, cada um a seu modo, estavam presos a um mercado conservador. Gutenberg dá um salto tecnológico imprimindo a Bíblia de 42 linhas, mas a produz em estilo gótico e incluindo um grande número de letras com pequenas alterações, ligaduras e abreviaturas. Sua intenção era tornar o texto o mais próximo possível das produções manuscritas, tentando agradar aos tradicionais leitores alemães. Manuzio estabelece uma grande quantidade de novos critérios para a produção de livros de alta qualidade, ainda hoje mantidos, e assume uma tipografia mais regularizada e menos complexa de estilo humanista para as letras latinas. No entanto, não procede da mesma maneira com as faces gregas. Talvez ambos, mesmo sabendo das grandes inovações que estavam produzindo e dos novos parâmetros que estavam ajudando a estabelecer, não quisessem ou não pudessem atuar de maneira diferente.

Após o trajeto, ao longo dos séculos que nos separam do início da imprensa ocidental, encontramos profissionais influentes e dispostos a resgatar conceitos e elementos, historicamente em oposição, como faz Zapf com as vertentes ortópticas e chancelerescas da tipografia grega. Seu trabalho respeita a cultura e a história, mas também é uma recusa a simplesmente repetir o que já foi criado anteriormente. Ora, ao lado de escritas minoritárias que correm o risco de desaparecer, existem outras de difusão mundial, como a grega, que, por uma série de circunstâncias, vêm sofrendo a ação predatória da globalização e da latinização imposta pelo design ocidental. Algo que nem Roma, após dominar a Grécia, ousou fazer. Cabe a nós, designers, cada vez mais envolvidos com criação tipográfica multiescrita, refletir sobre essas circunstâncias e agir no momento da criação, no sentido de garantir que a diversidade continue a existir.

\section{Agradecimentos}

Os autores agradecem a:

- Internet Arquive (www.archive.org) e aos seus parceiros pela distribuição gratuita dos livros que forneceram as imagens contidas nas figuras 4, 5, 6 e 7. Figura 4 extraída da pagina 29 de Robert \& Andrew Foulis and the Glasgow Press. Figura 5 extraída da página 14 de Novum Testamentum juxta exemplar Millianum. Figura 6 montada a partir de elementos das figuras 4 e 5 . Figura 7 extraída da página 3 de The Oresteia of Aeschylus; Agamemnon, Choephori, Eumenides.

- Oak Knoll Press, em especial ao Sr. Robert Fleck Jr., "Bob", e a Sra. Laura R. Williams, que gentilmente cederam os direitos de reprodução das imagens contidas nas figuras 1, 2, 3, 8, 9, 10, 12 e 13, originalmente incluídas no artigo de Hermann Zapf, The development of greek printing types, publicado no livro Greek letters.

— Greek Font Society (GFS), pela distribuição gratuita da fonte grega GFS Didot utilizada nas 
figuras 11 e 17.

- American Mathematics Society (AMS), pela distribuição gratuita da fonte grega Euler utilizada nas figuras 14 a 19.

\section{Referências}

Bowman, John H. Greek typography: the english contribution In: MACRAKIS, Michael S (org.). Greek letters: from tablets to pixels. New Castle: Oak Knoll Press, 1996. p. 129-144.

Bringhurst, Robert. Elementos do estilo tipográfico - versão 3.0. Tradução de André Stolarski. São Paulo: Cosac Naify, 2005. 428 p.

Carter, Matthew. Which came first, the greeks or the romans? In: MACRAKIS, Michael S (org.). Greek letters: from tablets to pixels. New Castle: Oak Knoll Press, 1996. p. 175-186.

Katsoulidis, Takis. The physiognomy of the greek typographical letter. In: MACRAKIS, Michael S (org.). Greek letters: from tablets to pixels. New Castle: Oak Knoll Press, 1996. p. 153-161.

Leonidas, Gerry. A primer on greek type design. In: BERRY, John D. (org). Language Culture Type: international type design in the age of Unicode. New York: ATypl \& Graphis, 2002. p. 76-90.

Matthiopoulos, George D.. Oblique or italics? A Greek typographical dilemma. In: MACRAKIS, Michael S (org.). Greek letters: from tablets to pixels. New Castle: Oak Knoll Press, 1996. p. 187-194.

Macrakis, Michael S (org.). Greek letters: from tablets to pixels. New Castle: Oak Knoll Press, 1996. $325 \mathrm{p}$.

Proctor, Robert. The printing of Greek in the fifteenth century. Oxford: Oxford University Press, 1900. 218 p. Cópia digitalizada pela Cornell University Library. Disponível em: <http://www.archive.org/details/cu31924029500414>. Acesso em: 24 mar. 2011.

Satué, Enric. Aldo Manuzio: editor, tipógrafo, livreiro. Tradução de Cláudio Giordano. Cotia: Ateliê Editorial, 2004.

Silva, S. L.; Lana, S.L.B.; SILVA, S. A. Considerações metodológicas sobre design tipográfico em multiescrita. In: 9o Congresso Brasileiro de Pesquisa e Desenvolvimento em Design 2010, São Paulo. Anais do 9ㅇ P\&D 2010. ISBN: 978-85-212-0566-1, p. 2233 - 2240. Disponível em: $<$ http://blogs.anhembi.br/congressodesign/anais/consideracoes-metodologicas-sobre-designtipografico-em-multiescrita > Acesso em: 24 mar. 2011.

Zapf, Hermann. The development of greek printing types. In: MACRAKIS, Michael S (org.). Greek letters: from tablets to pixels. New Castle, Oak Knoll Press, 1996. p. 3-29.

\section{Sobre os autores}

Sérgio Antônio Silva é Doutor em Letras: Estudos Literários pela Universidade Federal de Minas Gerais (UFMG); professor da Escola de Design da Universidade do Estado de Minas Gerais (UEMG), atuando na Graduação em Design Gráfico e no Mestrado em Design, com disciplinas, orientações e pesquisas ligadas à semiótica e às teorias da escrita. Leciona ainda no curso de Letras do Centro Universitário de Sete Lagoas. É autor de A hora da estrela de Clarice.

<sergio.antonio74@hotmail.com>

Sérgio Luciano da Silva é mestrando em Design pela Universidade do Estado de Minas Gerais, ED/UEMG, com o projeto "Faces e fontes multiescrita: fundamentos e critérios de design tipográfico". Suas pesquisas atuais envolvem estudos em filosofia, grego antigo, latim e hebraico. Sócio da Adaequatio Estúdio de Criação, atua principalmente com sinalização indicativa e interpretativa de cidades históricas, exposições de parques ambientais, projetos gráficos de livros e criação tipográfica multiescrita.

<sergiolucianosilva@gmail.com> 